\title{
Diversidade e eficiência das dinâmicas de criação de espaço e grau de cooperação entre as equipes de basquetebol paulistas: efeito da faixa etária
}

CDD. 20.ed. 796.017

796.32

\author{
Leonardo LAMAS* \\ Eduardo ROSTAISER* \\ Felipe SANTANA* \\ Valmor TRICOLI* \\ Carlos UGRINOWITSCH*
}

*Escola de Educação Física e Esporte,

Universidade de São

Paulo.

\section{Resumo}

0 objetivo deste trabalho foi avaliar o efeito da experiência competitiva sobre as seguintes variáveis de desempenho: 1) diversidade das dinâmicas de criação de espaço (DCEs) no setor defensivo; 2) eficiência das DCEs (i.e., frequência de êxito/total de execuções); 3) grau de cooperação ofensiva (i.e. número de passes e assistências). Foram analisados 46 jogos do Campeonato Paulista Masculino de Basquetebol (i.e. pré-mini a adulto). Variáveis medidas: 1) DCEs realizadas, que precederam o término da posse de bola em finalização, falta ou erro; 2) eficiência das DCEs; 3) passes em um ataque; 4) assistências. A reprodutibilidade foi testada pelo teste Kappa, tendo apresentado índices entre 0,78-0,85. A diversidade das DCEs não apresentou diferença significante para nenhuma classe de DCE entre todas as faixas etárias. $\mathrm{Na}$ análise intra-faixa etária, contra defesa individual, verificou-se significante predomínio de Desmarque com Bola com Drible para os mais jovens (pré-mini a infantil) e de Bloqueio Direto para os mais velhos (juvenil e adulto). Contra defesa zona, Desmarque sem Bola foi significantemente mais frequente em todas as faixas etárias em relação às demais DCEs, exceto Desmarque com Bola com Drible. Não foi verificada diferença significante para nenhuma das DCEs quanto à eficiência entre todas as faixas etárias. Todas as faixas etárias apresentaram perfil semelhante quanto ao número de passes, assim como de assistências. Estes resultados contrariam a hipótese formulada que previa aumento da complexidade e diversificação das ações com o aumento da experiência competitiva dos jogadores. Estas evidências sugerem a necessidade de propostas metodológicas de ensino do jogo com foco no coletivo e na cooperação.

Unitermos: Dinâmicas de criação de espaço (DCEs); Oposição; Análise de jogo; Tática ofensiva; Reprodutibilidade.

\section{Introdução}

A dinâmica do jogo de basquetebol é definida pela disputa da bola por duas equipes com objetivos opostos e que realizam ações individuais e coletivas, a partir de decisões coordenadas, com o objetivo de retomar a bola quando estão na defesa ou finalizála à cesta em situação de ataque e assim vencer a oposição (GréHAigne \& GodBout, 1995). Neste contexto, a aquisição de proficiência no processo de decisão (i.e. percepção-decisão-ação) é fundamental à melhoria do desempenho, pois assim as decisões individuais ocorrem de forma compatível com o plano estratégico coletivo, tornando-se mais coordenadas entre os jogadores da mesma equipe (Vickers, 2007; Williams, Hodges, North \& BARTON, 2006). Além disso, a proficiência nos processos decisórios pode contribuir para que as estratégias de uma equipe sejam mais diversificadas, tornando a equipe menos previsível ao adversário. 
A coordenação das ações entre os jogadores assim como a realização de uma estratégia mais diversificada requer atletas aptos para sua realização (Mahlo, 1969; Olivera \& Ticó, 1992). Esta aptidão depende de um processo de longo prazo, envolvendo prática sistemática (WARD \& WILLIAMS, 2003) e metodologias de ensino-aprendizagem eficazes para desenvolvimento da expertise dos jogadores (FrenCH \& MCPHERSON, 1999). Verificase na literatura amplo debate sobre a eficiência de diferentes estratégias de ensino-aprendizagem dos conteúdos do basquetebol (Ros \& Oliva, 2005; Sandomingo \& Señor, 2006; Turner \& Martinek, 1999). Porém, as metodologias que permitem avaliar os resultados das diferentes estratégias de ensino-aprendizagem no desempenho dos atletas encontram-se ainda em estágio preliminar de desenvolvimento (GréHaigne, Godbout \& Bouthier, 1997; McGarry, Anderson, Wallace, Hughes \& Franks, 2002). A discussão sobre a transferência da aprendizagem adquirida nas sessōes de treinamento para o desempenho específico é carente de maior suporte teórico, sendo poucos os estudos voltados à abordagem do desempenho tático (Grehaigne, Godbout \& Bouthier, 1997; Lamas, De Rose Junior, Santana, Rostaiser, Negretti \& Ugrinowitsch, 2011; TAVARES \& GoMes, 2003).

LAMAs et al. (2011) validaram uma metodologia para análise da recorrência das açóes de ruptura da defesa pelo ataque. Neste estudo, todos os padrões de

\section{Materiais e métodos}

\section{Participantes}

Os participantes foram as equipes semifinalistas do Campeonato Paulista de Basquetebol Masculino - 2008, em todas as oito categorias etárias disputadas (TABELA 1). Nas categorias etárias pré-mini, mini, mirim e infantil os jogos avaliados ocorreram no quadrangular final. Já nas categorias etárias infantojuvenil, cadete, juvenil e adulto os jogos avaliados comportamentos ofensivos relacionados a esta finalidade foram classificados em diferentes classes, segundo três critérios: a) número de jogadores envolvidos, b) ação técnica executada, c) contexto de decisão. Ao todo, sete classes descrevem todos os possíveis comportamentos ofensivos dos jogadores relacionados à ruptura defensiva, e são denominadas dinâmicas de criação de espaço (DCEs). A aplicação de uma DCE por uma equipe tem sempre como objetivo final criar uma situação favorável para finalização. Com o aumento da experiência competitiva ao longo das faixas etárias, é esperado que ocorra maior diversificação das DCEs, devido à maior coordenação coletiva da equipe e versatilidade na construção do ataque para vencer a oposição, levando em conta as deficiências identificadas no adversário. Ainda, é esperado que a cooperação entre jogadores de uma mesma equipe se desenvolva com o aumento da experiência e, associado à diversificação das DCEs, contribua para aumentar a complexidade do jogo entre indivíduos mais experientes.

No entanto, a diversificação na utilização das DCEs com o aumento da experiência competitiva, assim como o aumento da cooperação entre jogadores da mesma equipe não foram ainda investigadas. Assim, o presente trabalho teve como objetivo avaliar: a) a recorrência das classes de DCEs empregadas, b) a relação das DCEs com o êxito no ataque, e c) o grau de cooperação entre os jogadores de uma mesma equipe, ao longo de todas as faixas etárias competitivas do basquetebol.

TABELA 1 - Faixa etária (em anos) e número de jogos, por faixa etária.

\begin{tabular}{lcccccccc}
\hline & Pré-mini & Mini & Mirim & Infantil & $\begin{array}{c}\text { Infanto- } \\
\text { Juvenil }\end{array}$ & Cadete & Juvenil & Adulto \\
\hline Idade (anos) & 12 & 13 & 14 & 15 & 16 & 17 & $18-19$ & Livre \\
$\mathrm{n}$ (jogos) & 6 & 6 & 6 & 5 & 8 & 5 & 6 & 4 \\
\hline
\end{tabular}




\section{Coleta e análise de dados}

Nas gravaçôes a câmera foi posicionada na arquibancada, no mínimo a cinco metros do nível do piso e no prolongamento da linha central de demarcação da quadra de jogo, com distanciamento suficiente para que as linhas laterais fossem simultaneamente enquadradas. Este ângulo de filmagem foi definido para otimizar o enquadramento dos jogadores e da bola. Nas filmagens foi utilizada uma câmera digital (JVC GZ-HM 320 ${ }^{\circledR}$ ).

A análise dos jogos foi iniciada após o término de todas as filmagens, sempre conduzida por um avaliador principal (experiência de cinco anos em análise de jogos de basquetebol) e um assistente. $\mathrm{O}$ avaliador principal foi responsável pela análise das seguintes variáveis a cada posse de bola: a) tipo de ataque; b) tipo de defesa; c) dinâmicas de criação de espaço (DCEs). O tipo de ataque foi subdividido em três categorias: 1) posicionado: oposição envolvendo todos os atacantes e defensores na meia-quadra ofensiva; 2) contra-ataque: superioridade numérica ofensiva na meia-quadra de ataque frente a uma defesa ainda não organizada; 3) não houve: situações de perda da posse de bola antes que houvesse a ação de criação de espaço para a finalização. Os tipos de defesa foram subdivididos em duas categorias: 1) individual: cada defensor era responsável por um dos atacantes; 2) por zona: cada defensor era responsável por uma área da quadra defensiva. As DCEs foram subdivididas em sete classes (LAMAS et al., 2011). Nos critérios de formação das classes, o número de jogadores fornece uma medida objetiva da coordenação inter-pessoal, o tipo de habilidade usada descreve a solução motora apresentada para vencer a oposição e o contexto da decisão indica a presença ou ausência de uma coordenação coletiva estabelecida previamente à execução da DCE.

As DCEs são descritas nas seguintes classes: 1) Desmarque com Bola com Drible: açôes individuais nas quais a vantagem espaço-temporal para finalização é criada pelo jogador com bola, sem a cooperação de companheiros; 2) Desmarque com Bola sem Drible: semelhante ao Desmarque com Bola com Drible, porém sem drible, usando apenas técnicas de fintas; 3) Isolamento no Perimetro: jogador com bola é isolado no perímetro, normalmente na área central da meia-quadra ofensiva próximo à linha dos três pontos, enquanto os quatro companheiros ocupam espaços laterais de maneira que os defensores mantenham distância do jogador com bola (comumente realizado no final das posses de bola, com o isolamento do melhor finalizador); 4) Isolamento Interior: similar ao Isolamento no Perímetro, porém na região do garrafão. Tanto o Isolamento no Perímetro quanto o Isolamento Interior são casos particulares do Desmarque com Bola com Drible e do Desmarque com Bola sem Drible, pois o espaço é criado numa situação de $1 \mathrm{x} 1$, porém, considerados de forma separada por causa da ação coordenada de toda a equipe; 5) Desmarque sem Bola: ação de dois jogadores, sendo que um cria o espaço e recebe o passe de seu companheiro (e.g., situações de "backdoor”); 6) Bloqueio Direto: um jogador se posiciona na trajetória do defensor de seu companheiro com bola, interrompendo a trajetória do defensor (i.e., bloqueio), criando assim espaço para o jogador com a bola; 7) Bloqueio Indireto: semelhante ao Bloqueio Direto, porém nenhum dos dois jogadores envolvidos na ação de bloqueio tem a posse da bola. Após a interrupção da trajetória do defensor pelo bloqueio, um terceiro companheiro dos jogadores de ataque passa a bola para o jogador livre de marcação.

$\mathrm{O}$ avaliador auxiliar responsabilizou-se pelas seguintes variáveis: a) resultado do arremesso; b) número de passes realizados no ataque; c) presença ou ausência de passe de finalização (i.e., assistência). A razão entre os arremessos convertidos em cesta a partir de uma DCE pelo total de vezes que a DCE foi empregada em todas as posses de bola analisadas caracterizou a variável de eficiência das DCEs utilizada no presente estudo.

\section{Reprodutibilidade da análise}

A reprodutibilidade da análise do avaliador principal foi testada com a estatística Kappa (LANDIS $\&$ KocH, 1977). Para tanto, selecionou-se uma amostra de 70 posses de bola nas quais a consistência do avaliador foi testada para as variáveis sob sua responsabilidade na coleta de dados: a) tipo de ataque; b) tipo de defesa; c) DCEs. A análise de cada uma das posses foi realizada em três momentos distintos, separados por uma semana para eliminar um possível efeito de memória. Todos os vídeos foram reproduzidos em um DVD (Philips ${ }^{\circledR}$ ) e visualizados em uma televisão de 42 polegadas. $\mathrm{O}$ avaliador era autorizado e encorajado a rever uma posse de bola quantas vezes fossem necessárias até que houvesse certeza quanto à qualificação do lance analisado.

O índice mínimo assumido "a priori" de consistência na reprodutibilidade foi de 0,75 para que a análise pudesse ser conduzida. A partir da estatística Kappa empregada obtivemos os índices 
de 0,78/0,85/0,85 para o avaliador principal nas três semanas de avaliação, o que o habilitou a realizar a análise das posses de bola.

\section{Procedimento estatístico}

Os dados foram inicialmente filtrados por faixa etária. Para cada faixa etária as seguintes variáveis foram analisadas: tipos de ataque, tipos de defesa,

\section{Resultados}

Para cada uma das faixas etárias se verifica significante prevalência de ataques posicionados, em relação aos contra-ataques e posses de bola nas quais $\mathrm{o}$ ataque não foi concluído $(\mathrm{p}<0,05)$, conforme indicado na FIGURA 1. Porém, entre as faixas etárias não foi verificada diferença entre as proporções de ocorrência dos tipos de ataque.
DCEs, número de passes na quadra de ataque, número de assistências realizadas, eficiência em cada DCE. Após, foi aplicada uma estatística de qui-quadrado, com análise de resíduos para identificação de significância na associação entre as frequências de cada nível das variáveis. Para tanto foram utilizados os programas estatísticos $S A S^{\circledR} 9.2$ e PEPI ${ }^{\circledR} 4.01 \mathrm{O}$ nível de significância assumido foi de $\mathrm{p}<0,05$.
Em relação às preferências defensivas (FIGURA 2), nas categorias pré-mini e mini, a defesa zona foi significantemente mais utilizada que a defesa individual $(\mathrm{p}<0,05)$. Já no mirim, infantil, infantojuvenil e cadete as proporçóes se equilibraram e no juvenil e adulto ocorreu uma inversão com predomínio de defesa individual $(\mathrm{p}<0,05)$.

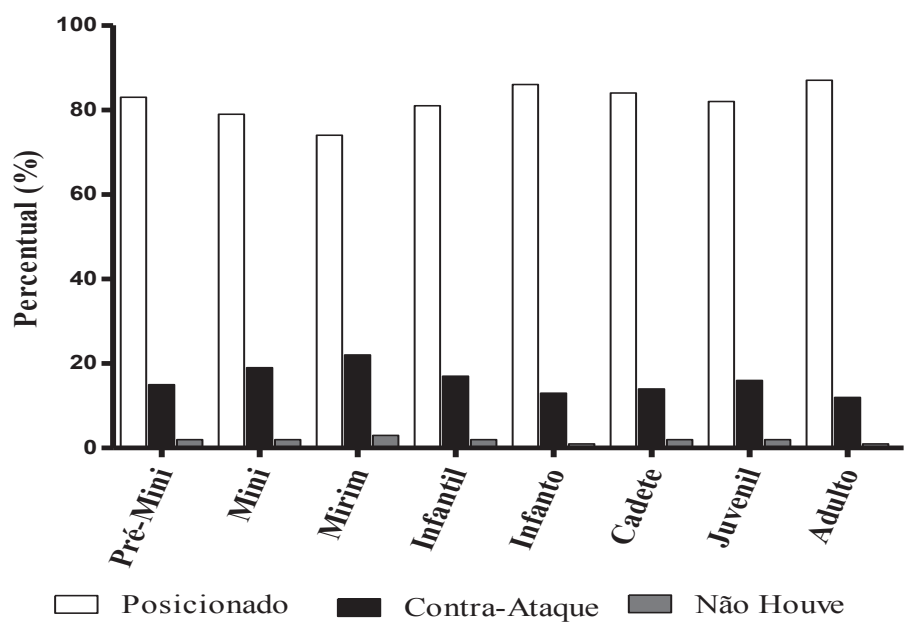

FIGURA 1 - Frequência relativa dos tipos deataque (posicionado, contra-ataque, enão houve) em cada faixa etária. 


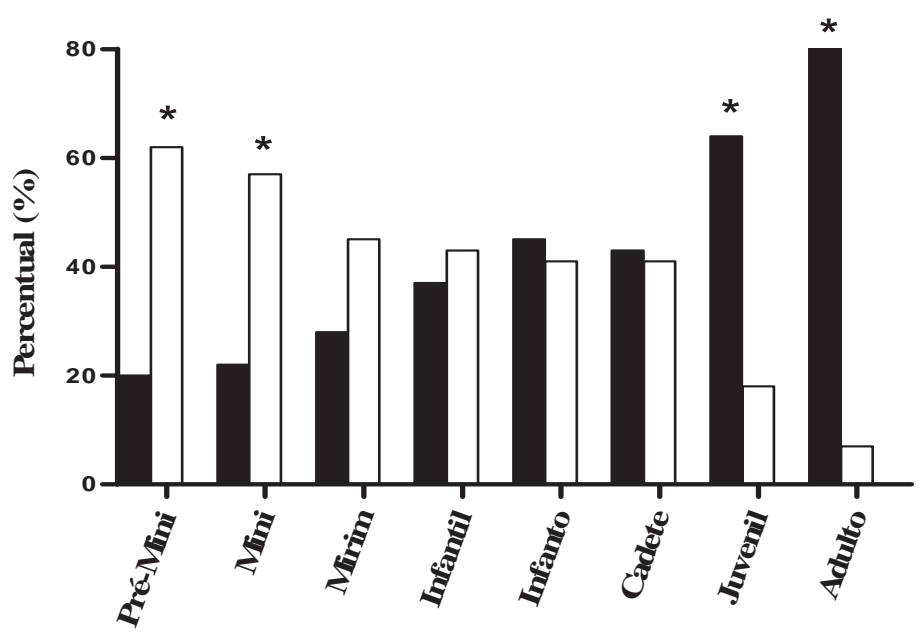

Individual

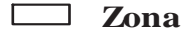

FIGURA 2 - Frequência dos tipos de defesa, individual ou zona, por faixa etária.

Não foram encontradas diferenças significantes entre as faixas etárias para a ocorrência de nenhuma das classes de DCEs contra defesa individual (FIGURA 3). Porém na análise das idades isoladamente, no pré-mini, mini e mirim a frequência de Desmarque com Bola com Drible foi maior que todas as demais $(p<0,05)$. Para o infantil, a frequência de Desmarque com Bola com Drible não foi maior apenas que Bloqueio Direto $(\mathrm{p}<0,05)$. No infanto, Desmarque com Bola com Drible teve frequência maior apenas em relação a Desmarque com Bola sem Drible, Isolamento no Perímetro e Isolamento Interior e o Bloqueio Direto apresentou frequência mais elevada que Isolamento no Perímetro $(\mathrm{p}<0,05)$. No cadete foi verificado maior equilíbrio entre as frequências de DCEs, sendo Desmarque com Bola com Drible maior apenas que Desmarque sem Bola e Bloqueio Indireto $(\mathrm{p}<0,05)$. Além disso, somente Bloqueio Direto ocorreu mais vezes que Isolamento no Perímetro ( $p$ $<0,05)$. No juvenil e adulto, Desmarque com Bola com Drible foi significantemente mais frequente que Desmarque com Bola sem Drible, Isolamento no Perímetro, Isolamento Interior e Desmarque sem Bola $(p<0,05)$. E Bloqueio Direto foi mais frequente que Desmarque com Bola sem Drible, Desmarque sem Bola, Isolamento Interior e Isolamento no Perímetro $(\mathrm{p}<0,05)$.

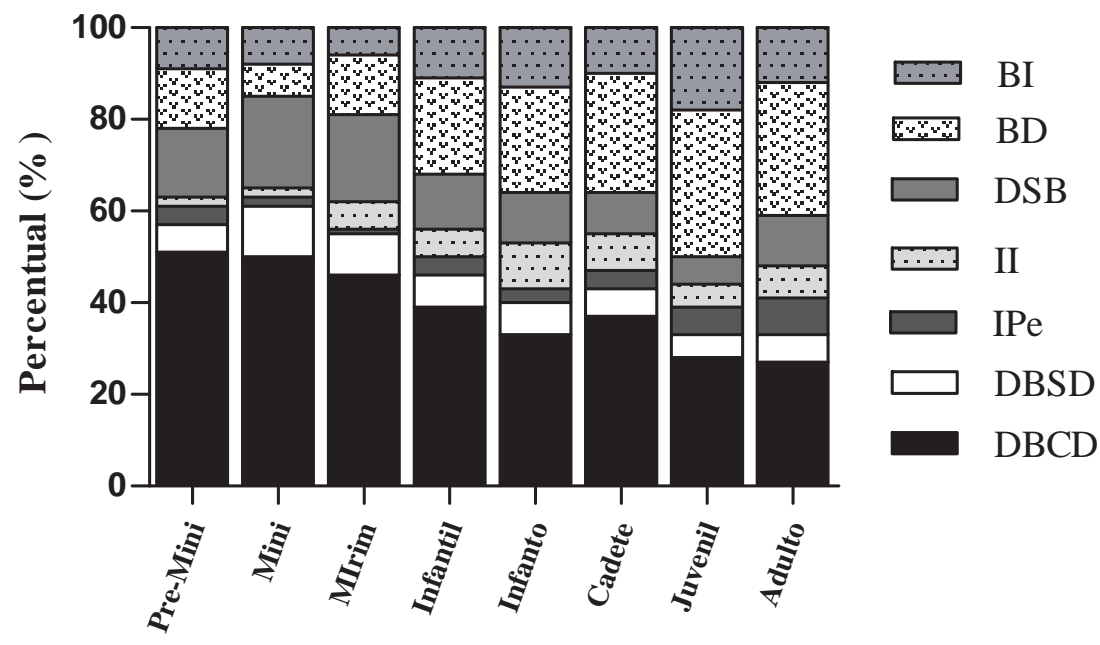

$\mathrm{DBCD}=$ Desmarque com Bola com Drible; DBSD = Desmarque com Bola Sem Drible; $\mathrm{IPe}=$ Isolamento no Perímetro;

II = Isolamento Interior; DSB = Desmarque sem Bola;

$\mathrm{BD}=$ Bloqueio Direto; $\mathrm{BI}=$ Bloqueio Indireto

FIGURA 3 - Dinâmicas de criação de espaço (DCEs) realizadas em posses de bola contra defesa individual. 
A frequência das DCEs para ações ofensivas contra defesa zona é apresentada na FIGURA 4. Assim como verificado contra defesa individual, contra defesa zona não foram encontradas diferenças significantes entre as faixas etárias para a ocorrência de nenhuma das classes de DCEs. Na análise de cada faixa etária, prémini, mini, mirim, infantil, infanto, cadete, juvenil e adulto apresentaram maior frequência de Desmarque com Bola com Drible do que todas as demais DCEs $(\mathrm{p}<0,05)$, exceto Desmarque sem Bola. Em todas estas faixas etárias o Desmarque sem Bola apresentou frequência superior a Desmarque com Bola sem Drible, Isolamento no Perímetro, Isolamento Interior, Bloqueio Direto e Bloqueio Indireto $(p<0,05)$.
$\mathrm{DBCD}=$ Desmarque com Bola com Drible; DBSD = Desmarque com Bola Sem Drible; $\mathrm{IPe}=$ Isolamento no Perímetro;

II = Isolamento Interior; DSB = Desmarque sem Bola;

$\mathrm{BD}=$ Bloqueio Direto; $\mathrm{Bl}=$ Bloqueio Indireto

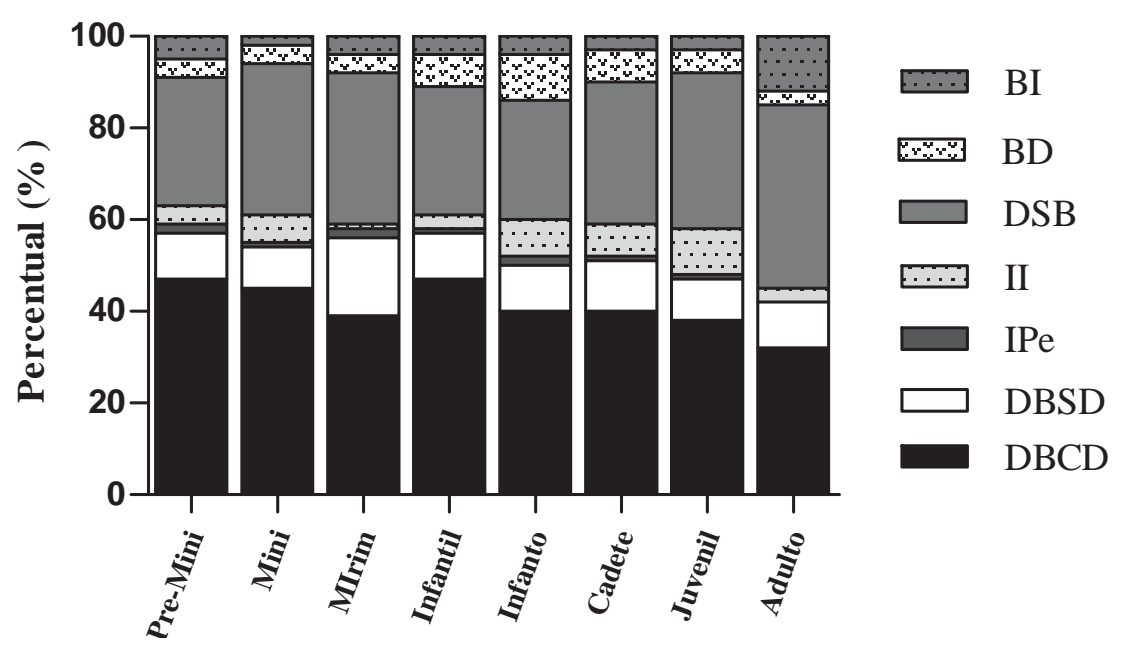

FIGURA 4 - Dinâmicas de criação de espaço (DCEs) realizadas em posses de bola contra defesa por zona.

A eficiência por faixa etária na utilização das DCEs foi determinada a partir da proporção entre a frequência de êxitos na finalização decorrente da realização da DCE e a frequência total de ocorrência da DCE em questão (FIGURA 5). Não foi verificada nenhuma diferença significante para a eficiência de uma dada DCE entre as diferentes idades. Assim como não foi encontrada diferença significante para a eficiência de uma DCE em uma mesma idade para os dois tipos de defesa. Apenas o Isolamento no Perímetro e Isolamento Interior na categoria mirim, contra defesa individual, apresentaram eficiência superior às demais DCEs na mesma idade e contra o mesmo tipo de defesa $(\mathrm{p}<0,05)$. 
Pre-mini
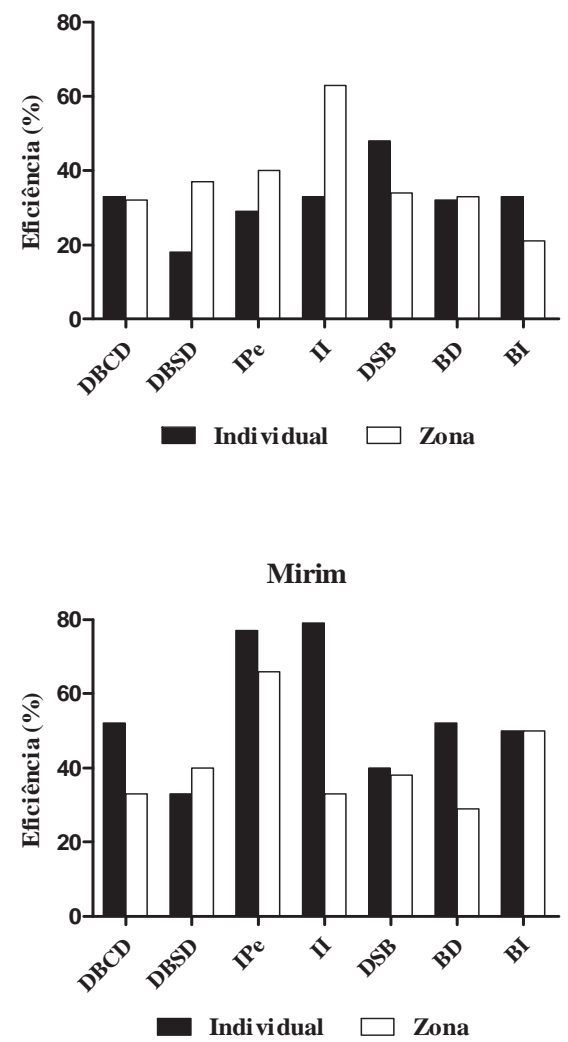

Infanto

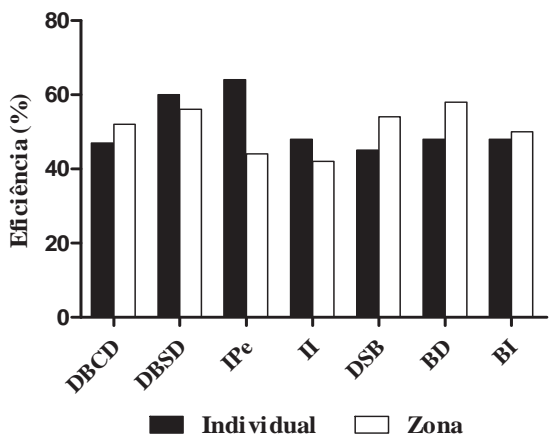

Juvenil

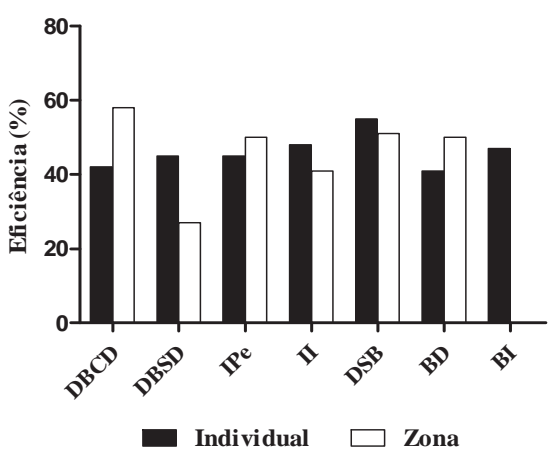

Mini

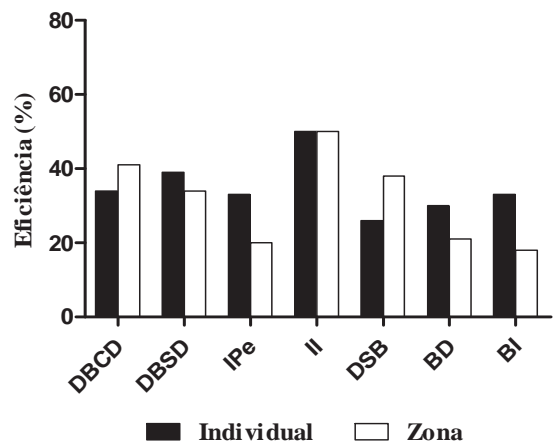

Infantil

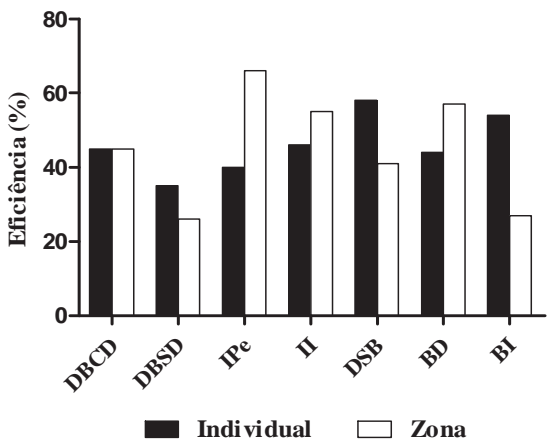

Cadete

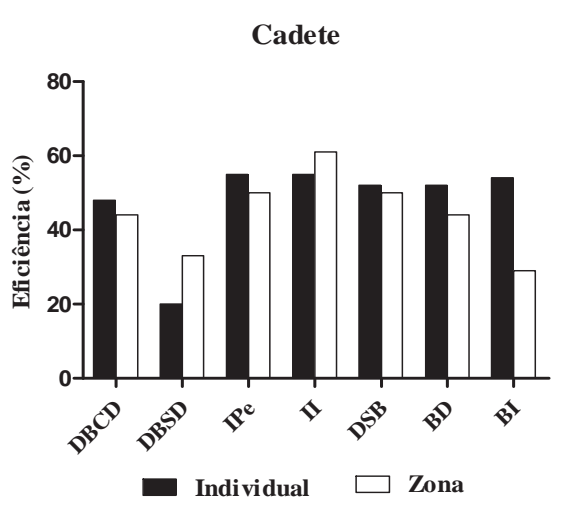

Adulto

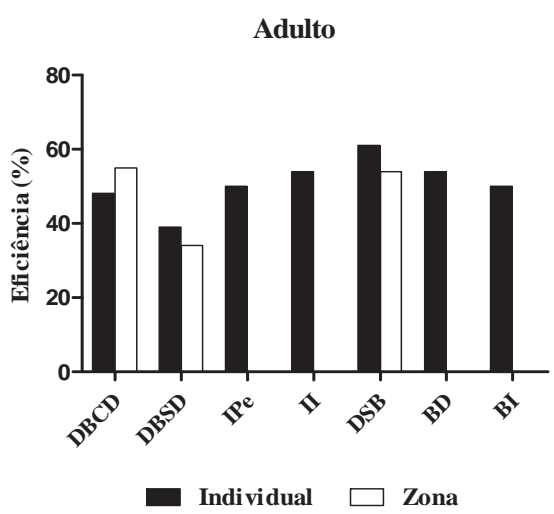

$\mathrm{DBCD}=$ Desmarque com Bola com Drible; DBSD = Desmarque com Bola Sem Drible; $\mathrm{IPe}=$ Isolamento no Perímetro;

II = Isolamento Interior; $\mathrm{DSB}=$ Desmarque sem Bola;

$\mathrm{BD}=$ Bloqueio Direto; $\mathrm{BI}=$ Bloqueio Indireto

FIGURA 5 - Eficiência, por faixa etária, das DCEs. 
A FIGURA 6 ilustra o número de passes realizados entre os jogadores de uma mesma equipe em cada faixa etária, contra defesa individual e zona. No presente estudo foi registrada uma frequência máxima de 10 passes em uma mesma posse de bola. Porém, a frequência percentual acumulada de oito passes ou mais foi inferior a $3 \%$ em todas as categorias. Portanto, para possibilitar melhor visualização das figuras optouse por apresentar a frequência de posses de bola com até sete passes. Os perfis são bastante homogêneos entre as faixas etárias. Contra defesa individual há tendência de queda na proporção de passes realizados e contra defesa zona há maior estabilidade entre as proporçōes para as diferentes frequências de passes.
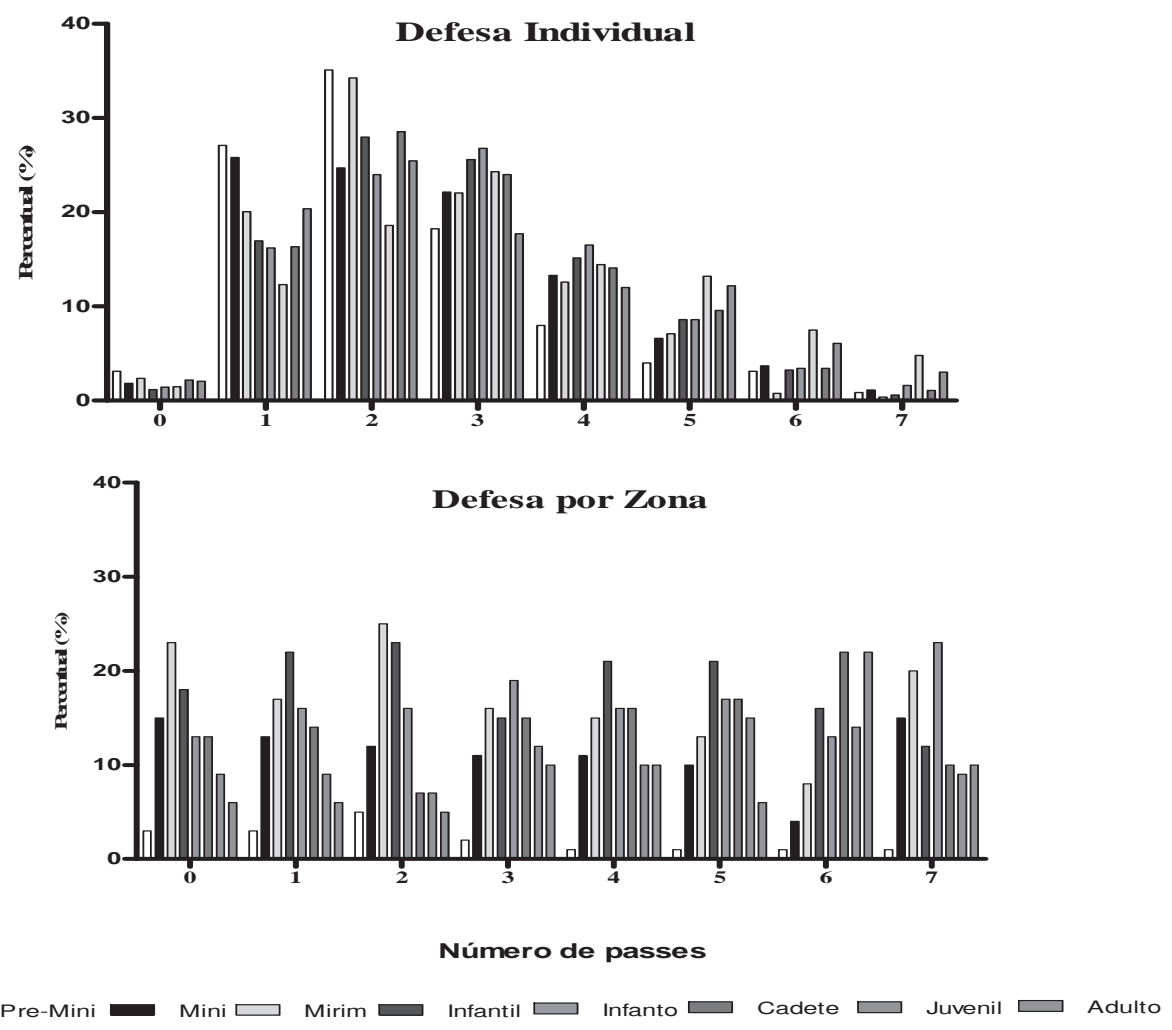

FIGURA 6 - Número de passes por faixa etária contra defesa individual e defesa por zona.

A frequência de assistências (passe que precede a finalização convertida em cesta) perante o total de ataques por faixa etária é apresentada na FIGURA 7. Não foi verificada diferença significante entre as frequências relativas de assistências para nenhuma faixa etária e para nenhum dos tipos de defesa. Entre faixas etárias também não foi constatada nenhuma diferença significante, embora se verifique uma tendência ao aumento do número de assistências para faixas etárias mais elevadas, para os dois tipos de defesa. 


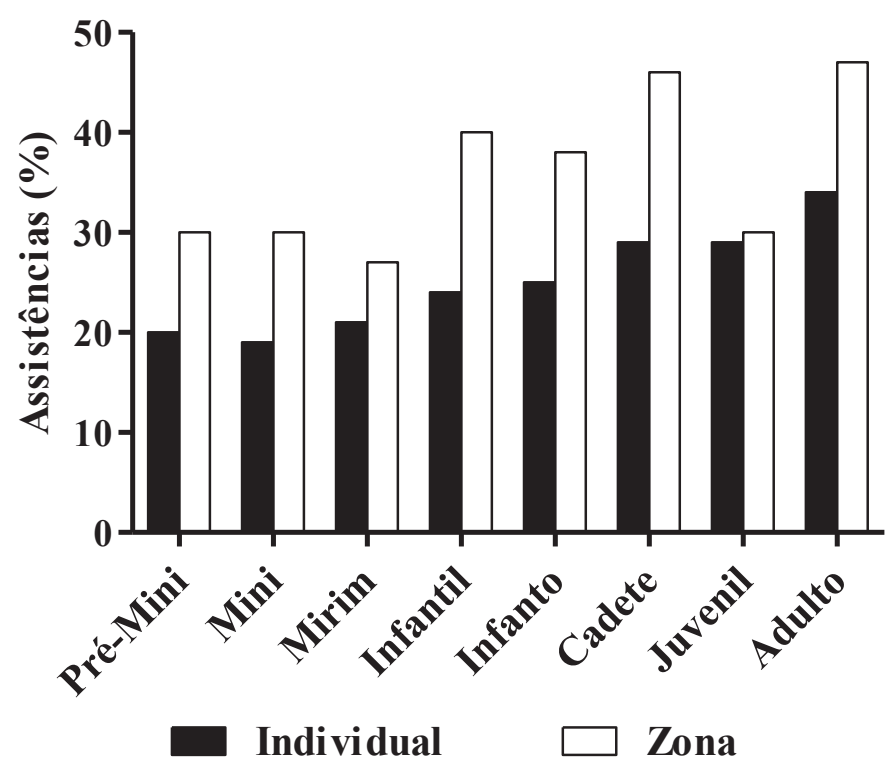

FIGURA 7 - Frequência relativa (\%) de assistências realizadas frente ao total de ataques efetuados, para cada faixa etária, contra cada tipo de defesa

\section{Discussão}

O principal resultado do presente estudo foi que todas as faixas etárias investigadas apresentaram perfil semelhante de atuação, quanto à frequência de DCEs utilizadas, sua eficiência e grau de cooperação. Apenas o tipo de defesa parece modular as recorrências de DCEs, verificando-se predomínio de Desmarque com Bola com Drible e Bloqueio Direto contra defesa individual e Desmarque com Bola com Drible e Desmarque sem Bola contra defesa por zona. A eficiência das DCEs também apresentou padrão relativamente homogêneo entre as faixas etárias. Além disso, os índices de cooperação, expressos pelo número de passes no ataque e número de assistências, também apresentaram comportamento semelhante entre as idades, sendo que o número de passes apresentou diferenças apenas em função do tipo de defesa.

A dinâmica da oposição entre as equipes indica predomínio de ataques posicionados em todas as faixas etárias, corroborando com os resultados de OrTEGA, Palao, Gómez, Lorenzo e Cárdenas (2007). Já o tipo de defesa praticado nos ataques posicionados sofreu alterações em função da faixa etária. Verificou-se predomínio da defesa por zona entre os mais jovens (pré-mini e mini, $\mathrm{p}<0,05)$ e predomínio da defesa individual entre os mais velhos (juvenil e adulto, $p<0,05$ ), sendo que o aumento da participação da defesa individual é gradual ao longo das faixas etárias (FIGURA 2).
Estes dois tipos de defesa possuem diferenças em suas concepções teóricas, assim como em suas dinâmicas, que implicam na defesa de um jogador específico (defesa individual) ou zona da quadra específica (defesa por zona). É possível que um motivo para o predomínio de defesa por zona entre os mais jovens seja a vantagem estratégica adquirida ao concentrar os defensores em regióes mais próximas à cesta, forçando o ataque a finalizar a partir de regiōes mais distantes, nas quais a eficiência é menor para indivíduos mais jovens conforme demonstrado por Okazaki, Rodacki, Dezan e Sarraf (2006).

Uma vez que se observa o predomínio da defesa por zona em faixas etárias mais jovens e defesa individual em idades mais avançadas, estudos futuros podem investigar as características das defesas praticadas em cada faixa etária. Por exemplo, os tipos de ajudas, rotaçôes e dobras praticadas que distinguem os variados tipos de defesas individuais, assim como as diferentes configurações iniciais empregadas (e.g. 2:3, 1:3:1, etc) e também os tipos de ajuda, rotaçōes e dobras que diferenciam as defesas por zona. As descobertas resultantes podem contribuir para fundamentar a discussão sobre alterações regulamentares, empiricamente testadas por federaçôes no Brasil e no exterior, que ora restringem ora autorizam a utilização da defesa por zona em faixas etárias mais novas. 
Em relação à diversidade das DCEs, não foram verificadas diferenças nas suas frequências entre as faixas etárias para cada um dos tipos de defesa analisados (i.e., individual ou por zona). Estes resultados indicam que, embora a amostra investigada tenha sido composta por todo o espectro de níveis de experiência possível (i.e. pré-mini ao adulto), as ações preferenciais utilizadas para vencer a oposição e gerar finalização foram semelhantes, quando considerado um tipo de defesa em particular. Decorre desta constatação a possível existência de DCEs preferenciais em detrimento de outras. As DCEs preferenciais para ataques contra defesa individual (Desmarque com Bola com Drible e Bloqueio Direto) corroboram com os resultados de REMMERT (2003), cuja amostra apresentou predominância dos mesmos tipos de açôes nas tentativas de ruptura da defesa. Contra defesa por zona, em nossos resultados o Desmarque com Bola se mantém como uma ação predominante, além do Desmarque sem Bola. Uma vez que defesas por zona protegem áreas específicas da quadra, a ocupação de espaços vazios da quadra pelos atacantes faz com que o Desmarque sem Bola seja uma ação recorrente na tentativa de ruptura do sistema defensivo.

Entretanto, contra nenhum dos tipos de defesa as DCEs mais utilizadas apresentaram eficiência superior às demais DCEs (FIGURA 6). Esta evidência indica uma possível incoerência nas instâncias de decisão estratégica e tática das equipes, quanto à escolha e execução de um conjunto restrito de açóes ofensivas de ruptura defensiva que não resultaram em maior eficiência que as outras DCEs menos utilizadas.

É possível associar a utilização preferencial de certas DCEs a algumas características da oposição. No caso da predominância de Desmarque com Bola com Drible em relação a todas as demais DCEs verificadas do pré-mini ao infantil contra defesa individual e do pré-mini ao adulto contra defesa zona, com exceção feita ao Desmarque sem Bola, dois fatores podem ser relacionados. Nas faixas etárias mais novas a defesa possui maior fragilidade, sendo frequente que os jogadores apresentem falta de condicionamento para manter uma boa postura defensiva e movimentar-se com velocidade nos deslocamentos laterais. Além disso, nestas idades a tática coletiva defensiva (i.e. ajudas e rotaçôes) costuma ser simplificada aumentando as chances de sucesso de ações ofensivas individuais. Ainda, nestas idades é esperado que os atacantes tenham menor capacidade de coordenar suas ações conjuntas, o que pode contribuir para explicar a menor frequência de bloqueios e isolamentos, recorrendo-se então a ações individuais por meio do Desmarque com Bola com Drible. É comum também que certas equipes possuam jogadores mais hábeis que os demais, os quais recorrem ao Desmarque com Bola com Drible para finalizar $o$ ataque. Este argumento pode contribuir inclusive para explicar porque o Desmarque com Bola com Drible, embora tenha diminuído com o aumento da idade, continuou como uma das DCEs mais utilizadas até a categoria adulta, correspondendo a $51 \%$ no pré-mini, $39 \%$ no infantil e $27 \%$ no adulto contra defesa individual e $47 \%$ no pré-mini, $47 \%$ no infantil e $32 \%$ no adulto contra defesa por zona.

A frequência do Bloqueio Direto contra defesa individual pode ser explicada por argumento semelhante. Trata-se de uma DCE que favorece a ação de um jogador habilidoso em posse de bola que se vale de um bloqueio (i.e. obstrução do deslocamento de seu defensor realizado por um de seus companheiros de equipe) para ensejar uma boa situação de finalização para si ou para o colega que efetuou o bloqueio. O perfil crescente, embora não significantemente diferente de sua utilização - pré-mini: 13\%, infantil: $21 \%$ e adulto: $29 \%$ - indica a necessidade de maior elaboração do ataque em relação à ação de Desmarque com Bola com Drible para vencer a oposição defensiva, mas também uma ênfase na utilização do potencial ofensivo dos melhores jogadores, já que DCEs envolvendo a coordenação de mais jogadores (e.g., Bloqueio Indireto, Isolamento Interior, Isolamento no Perímetro) não foram tão frequentes quanto o Bloqueio Direto, em especial em categorias mais velhas. A elevada frequência de utilização do Bloqueio Direto em equipes de diferentes idades já havia sido verificada em outros estudos (REFoYo, DomíngueZ, Sampedro, Del Campo, 2009; Romero, 2010).

O aumento do Bloqueio Direto em relação ao Desmarque com Bola com Drible verificado contra defesa individual encontra paralelo na tendência de aumento do Desmarque sem Bola em relação à defesa zona, tendo sido contabilizado para o prémini: $28 \%$, infantil: $28 \%$ e adulto: $40 \%$. Ações típicas de Desmarque sem Bola envolvem cortes sem bola e posterior recepção da mesma pelo jogador que realizou o corte, assim como posicionamentos estratégicos para distanciar-se da marcação quando se atua contra defesas zona, ocupando os espaços vazios que este tipo de defesa suscita. Assim, em categorias mais novas nas quais as táticas defensivas individuais e coletivas se encontram em estágio mais rudimentar de aprendizagem, a realização de ações de Desmarque sem Bola a partir de posicionamentos ofensivos adequados pode ser favorecida. 
Além dos fatores considerados, é possível que o processo de treinamento também influencie na utilização preferencial de certas DCEs. Contextos abertos de treinamento, envolvendo prática deliberada incentivam a criatividade (Greco, Memmert \& Morales, 2010) e tomadas de decisão mais diversificadas do que aqueles submetidos à prática com situações programadas (FrENCH \& MCPHERSON, 1999; Ros \& Oliva, 2005). Porém, atualmente há predomínio do treinamento analítico, com ênfase técnica, em ambientes fechados de prática em detrimento de abordagens voltadas à resolução de problemas (Williams \& Hodges, 2005), nas quais o jogador precisa optar por uma alternativa, dentre várias, de acordo com o contexto (SANDOMINGo \& SeÑor, 2006). Isto pode refletir não só em menor diversidade de açôes, devido à capacidade restrita de compreender as variações do ambiente, no contexto da oposição, como também restringir o desenvolvimento da coordenação inter-pessoal dos jogadores de uma mesma equipe, pois o caráter coletivo das decisões tomadas e, consequentemente sua eficiência, dependem da correta interpretação do contexto (Passos, Araújo, Davids, Gouveia, Milho \& Serpa, 2008; Passos, Milho, Fonseca, Borges, Araújo \& Davids, 2011).

Nossos resultados demonstram uma pequena tendência ao aumento da diversidade das DCEs com o aumento da experiência, o que pode refletir a aprendizagem de outras formas de atuar. Assim, o prolongamento do tempo de prática pode, mesmo que de forma não planejada e controlada, contribuir para a diversificação das ações de jogo. Esta diversificação parece ser positiva, pois implica em maior imprevisibilidade da ação ofensiva da equipe frente ao adversário.

A ação de Isolamento no Perímetro apresentou no mirim os maiores valores de eficiência dentre as DCEs em todas as idades (contra defesa individual e zona, respectivamente: $77 \%$ e $66 \%$ ). Já o Isolamento Interior apresentou comportamento semelhante contra defesa individual, com o índice de $79 \%$ de eficiência, mas não contra defesa zona, cuja eficiência foi de $33 \%$. O resultado inferior obtido contra defesa zona corrobora com a perspectiva de utilização desta defesa para limitar as possibilidades de açôes no interior do garrafão, que é o objetivo do Isolamento Interior. De modo geral, os resultados de eficiência nos isolamentos podem ter relação com a presença de um ou mais jogadores com alta produtividade nas açóes de $1 \mathrm{x} 1$ no interior do garrafão ou no perímetro, gerando mais ações de isolamento por parte da equipe. Porém, nem todas as equipes possuem jogadores com estas características, assim como defesas elaboradas podem ter melhores condições de neutralizá-las. Isso pode explicar a variação da eficiência encontrada para essas DCEs nas demais idades.

Os índices de cooperação analisados indicaram significativa distinção no perfil dos passes em função do tipo de defesa. Contra defesa individual há clara tendência de queda da frequência de posses de bola nas quais muitos passes foram realizados, com predominância de dois a três passes em cada posse de bola. Estes valores são próximos aos 3,3 passes, em média, por posse de bola encontrados por ORTEGA et al. (2007) entre equipes de basquetebol de 16 anos na Espanha. Já no jogo contra defesa por zona, o perfil é homogêneo entre todas as frequências de passes. Houve poucas posses de bola com poucos passes (um a dois) ou muitos passes (seis a sete). Quanto às assistências, verificaram-se diferenças significantes para todas as faixas etárias em função do tipo de defesa, com maior percentual de ataques finalizados a partir de assistências em ataques contra defesa por zona. Este perfil pode ser explicado possivelmente pela maior quantidade de passes realizados quando se joga contra esse tipo de defesa, pois passar a bola e deslocar-se é uma estratégia frequentemente recomendada para atacá-la. Tal procedimento ofensivo propicia a ocorrência de assistências.

É possível concluir que há grande homogeneidade nas ações ofensivas de ruptura do sistema defensivo entre as diferentes faixas etárias, sendo semelhantes tanto as frequências das DCEs, quanto o aproveitamento das oportunidades de finalização decorrentes, e o grau de cooperação entre os jogadores da mesma equipe. Estes resultados contrariam a hipótese formulada que previa aumento da complexidade e diversificação das ações com o aumento da experiência competitiva dos jogadores. O padrão homogêneo de atuação ofensiva não pode ser justificado pela eficiência das ações mais utilizadas, pois esta variável teve resultado semelhante para todas ações ofensivas analisadas. É possível que maior diversidade pudesse resultar em maior eficiência por gerar maior imprevisibilidade à defesa. O perfil generalizado de baixa demanda de coordenação inter-pessoal é ainda mais marcante nas faixas etárias menores, mas também ocorre entre os mais velhos. Em todas as faixas etárias verificou-se, da mesma forma, baixo grau de cooperação.

Portanto, os resultados quantitativos do presente estudo fornecem suporte teórico para a discussão sobre as necessidades do processo formativo do jogador de basquetebol. Em especial, quanto ao desenvolvimento de ações progressivamente mais 
elaboradas e diversificadas, nas quais todos estejam envolvidos. Ações com poucos jogadores são mais fáceis de ensinar e, em certos casos, difíceis de marcar. Porém, seja quando objetivo é vencer ou, especialmente, quando o objetivo é a formação do jogador, açôes coletivas produzem um jogo mais diversificado e inteligente do que ações individuais permitem realizar. $\mathrm{O}$ foco no desenvolvimento das açôes coletivas de uma equipe conduz à maior elaboração dos conteúdos táticos através de um processo de treinamento baseado na premissa de que o basquetebol é, na essência, um jogo coletivo.

\title{
Nota
}

Os autores Leonardo Lamas e Eduardo Rostaiser contribuíram igualmente para o trabalho.

\begin{abstract}
Diversity and efficiency of the space creation dynamics and cooperation rate in basketball teams: age effect

The aim of the present study was to evaluate the effect of competitive experience in the following performance variables: 1) diversity of the Space Creation Dynamics (SCDs); 2) efficiency of the SCDs (i.e. successful SCDs/total amount of SCDs); 3) offensive cooperation (i.e. number of passes and assists). A total of 46 matches of all age goups (i.e. pré-mini to seniors) of the São Paulo state championship for men were analyzed. Measured/ calculated variables: 1) SCDs performed; 2) SCDs efficiency; 3) passes performed on ball possession; 4) assists performed. Researcher's reliability was tested in three moments with one week apart of each other (Kappa rates: 0.78-0.85). SCDs diversity presented no significant difference for any SCD class among all age groups. Intra-age analysis, against man-to-man defense, presented significant prevalence of "Desmarque com Bola com Drible" for younger players (pré-mini to infantil) and of "Bloqueio Direto" for older players (juvenil and seniors). Against zone defense, "Desmarque sem Bola" was significantly more frequent for all age groups in comparison to all others SCDs, except for "Desmarque com Bola com Drible". It was not observed a significant difference for efficiency of the SCDs at any age group. All age groups presented similar distribution regarding frequencies of number of passes and assists as well. These results contradicted the preliminary hypothesis, which expected an increase in complexity and diversity of actions paralleled with an increase in players' competitive expertise. These evidences suggest the need of cooperation and collective-focused teaching games methodology.

UnITERMS: Space creation dynamics (SCDs); Opposition; Game analysis; Offensive tactics; Reproducibility.
\end{abstract}

\section{Referências}

FRENCH, K.E.; McPHERSON, S.L. Adaptations in response selection processes used during sport competition with increasing age and expertise. International Journal of Sport Psychology, Roma, v.30, p.173-93, 1999.

GRECO, P.; MEMMERT, D.; MORALES, J.C. The effect of deliberate play on tactical performance in basketball. Perceptual and Motor Skills, Missoula, v.110, n.3, p.849-56, 2010.

GRÉHAIGNE, J.F.; GODBOUT, P. Tactical knowledge in team sports: from a constructivist and cognitivist perspective. Quest, Champaign, v.47, p.490-505, 1995.

GRÉHAIGNE, J.F.; GODBOUT, P.; BOUTHIER, D. Performance assessment in team sports. Journal of Teaching in Physical Education, Champaign, v.16, p.500-16, 1997.

LAMAS, L.; De ROSE JUNIOR, D.; SANTANA, F., ROSTAISER, E.; NEGRETTI, L.; UGRINOWITSCH, C. Space creation dynamics in basketball offence: validation and evaluation of elite teams. International Journal of Performance Analysis in Sport, Cardiff, v.11, n.1, p.71-84, 2011.

704 • Rev. bras. Educ. Fís. Esporte, São Paulo, v.25, n.4, p.693-705, out./ dez. 2011 
LANDIS, J.R.; KOCH, G. The measurement of observer agreement for categorical data. Biometrics, Alexandria, v.33, p.159-74, 1977.

MAHLO, F. L'actetactique en jeu. Paris,Vigot Fréres Editeurs, 1969.

McGARRY, T.; ANDERSON, D.I.; WALLACE, S.A.; HUGHES, M.; FRANKS, I. Sport competition as a dynamical self-organizing system. Journal of Sports Sciences, London, v.20, p.771-81, 2002.

OKAZAKI, V.H.A.; RODACKI, A.L.F.; DEZAN, V.H.; SARRAF, T.A. Coordenação do Arremesso de Jump no Basquetebol de Crianças e Adultos. Revista Brasileira de Biomecânica, São Paulo, v.7, p.15-22, 2006.

OLIVER, D. Basketball on paper: rules and tools for performance analysis. Washington: Potomac, 2004.

OLIVERA, J.; TICÓ, J. Análisis funcional del baloncesto como deporte de equipo. Apunts: Educación Física y Deportiva, Barcelona, v.27, p.34-46, 1992.

ORTEGA, E.; PALAO, J.M.; GÓMEZ, M.A.; LORENZO, A.; CÁRDENAS, D. Analysis of the efficacy of possessions in boys' 16-and-under basketball teams: differences between winning and losing teams. Perceptual and Motor Skills, Missoula, v.104, p.961-4, 2007.

PASSOS, P.; ARAÚJO, D.; DAVIDS, K.; GOUVEIA, L.; MILHO, J.; SERPA, S. Information-governing dynamics of attacker-defender interactions in youth rugby union. Journal of Sports Sciences, London, v.26, n.13, p.1421-9, 2008. PASSOS, P.; MILHO, J.; FONSECA, S.; BORGES, J.; ARAÚJO, D.; DAVIDS, K. Interpersonal distance regulates functional grouping tendencies of agents in team sports. Journal of Motor Behavior, Washington, v.43, n.2, pp.155-63, 2011. REFOYO, I.; DOMÍNGUEZ, J.; SAMPEDRO, J.; DEL CAMPO, J. Análisis de la decisión táctica en el bloqueo directo: una comparación entre selecciones internacionales absolutas y clubes. Cuardernos de Psicologia del Deporte, Murcia, v.9, 2009. Suplemento 1.

REMMERT, H. Analysis of group-tactical offensive behavior in elite basketball on the basis of a process orientated model. European Journal of Sport Science, Birmingham, v.3, n.3, p.1-12, 2003.

ROMERO, J. Análisis de la decisión táctica en deportes colectivos: una aplicación al bloqueo directo en baloncesto. 2010. 247f. Tese (Doutorado) - Universidad Politécnica de Madrid, Madrid, 2010.

ROS, V.L.; OLIVA, F.J.C. La enseñanza integrada técnico-táctica de los deportes en edad escolar: explicación y bases de un modelo. Apunts: Educación Física y Desportiva, Barcelona, v.79, n.1, p.40-8, 2005.

SANDOMINGO, V.T.; SEÑOR, P.I.M. Aspectos metodológicos de la iniciación deportiva a los deportes de invasión: una aproximación horizontal. Apunts: Educación Física y Esports, Barcelona, v.83, n.1, p.35-42, 2006.

TAVARES, F.; GOMES, N. The offensive process in basketbal: a study in high performance junior teams. International Journal of Performance Analysis in Sport, Cardiff, v.3, n.1, p.34-9, 2003.

TURNER, A.P.; MARTINEK, P.J. An investigation into teaching games for understanding: effects on skill, knowledge, and game play. Research Quarterly for Exercise and Sport, Washington, v.70, n.3, p.286-96, 1999.

VICKERS, J. Perception, cognition, and decision training: the quiet eye in act. Champaign: Human Kinetics, 2007. WARD, P.; WILLIAMS, A.M. Perceptual and cognitive skill development in soccer: the multidimensional nature of expert performance. Journal of Sport and Exercise Psychology, Champaign, v.25, p.93-111, 2003.

WILLIAMS, AM.; HODGES, N.J. Practice, instruction and skill acquisition in soccer: challenging tradition. Journal of Sports Sciences, London, v.23, n.6, p.637-50, 2005.

WILLIAMS, A.M.; HODGES, N.J.; NORTH, J.S.; BARTON, G. Perceiving patterns of play in dynamic sport tasks: Investigating the essential information underlying skilled performance. Perception, London, v.35, n.3, p.317-32, 2006.

\section{Agradecimentos}

FAPESP, Processo 08/10810-1. 